\title{
Robotic mitral valve repairs in 300 patients: A single- center experience
}

\author{
W. Randolph Chitwood, Jr, MD, ${ }^{a}$ Evelio Rodriguez, MD, ${ }^{\text {a }}$ Michael W. A. Chu, MD, ${ }^{\text {a }}$ Ansar Hassan, MD, PhD, \\ T. Bruce Ferguson, MD, ${ }^{a}$ Paul W. Vos, PhD, ${ }^{b}$ and L. Wiley Nifong, MD ${ }^{a}$
}

From the Departments of Cardiovascular Sciences $^{\mathrm{a}}$ and Biostatistics, ${ }^{\mathrm{b}}$ East Carolina Heart Institute, East Carolina University, Greenville, NC.

Received for publication Jan 10, 2008; revisions received March 9, 2008; accepted for publication March 27, 2008.

Address for reprints: W. Randolph Chitwood, Jr, MD, Department of Cardiovascular Sciences, East Carolina University, 600 Moye Blvd, Greenville, NC 27858 (E-mail: chitwoodw@ecu.edu).

J Thorac Cardiovasc Surg 2008;136:436-41 0022-5223/\$34.00

Copyright $\odot 2008$ by The American Association for Thoracic Surgery

doi:10.1016/j.jtcvs.2008.03.053
Objectives: Mitral valve repair is the standard therapy for patients with degenerative (myxomatous) disease and severe mitral regurgitation. Robotic mitral valve repair provides the least-invasive surgical approach. We report the largest single-center robotic mitral valve repair experience.

Methods: Between May 2000 and November 2006, 300 patients underwent a robotic mitral valve repair (daVinci Surgical System; Intuitive Surgical, Inc, Sunnyvale, Calif). All operations were done with 3- to 4-cm right intercostal access, transthoracic aortic occlusion, and peripheral cardiopulmonary bypass. Repairs included 1 or a combination of trapezoidal/triangular leaflet resections, sliding plasties, chordal transfers/ replacements, edge-to-edge approximations, and ring annuloplasties. Echocardiographic and survival follow-up were $93 \%$ and $100 \%$ complete, respectively.

Results: There were $2(0.7 \%)$ 30-day mortalities and $6(2.0 \%)$ late mortalities. No sternotomy conversions or mitral valve replacements were required. Immediate postrepair echocardiograms showed the following degrees of mitral regurgitation: none/ trivial, 294 (98\%); mild, 3 (1.0\%); moderate, 3 (1.0\%); and severe, 0 (0.0\%). Complications included $2(0.7 \%)$ strokes, 2 transient ischemic attacks, $3(1.0 \%)$ myocardial infarctions, and $7(2.3 \%)$ reoperations for bleeding. The mean hospital stay was $5.2 \pm$ 4.2 (standard deviation) days. Sixteen (5.3\%) patients required a reoperation. Mean postoperative echocardiographic follow-up at $815 \pm 459$ (standard deviation) days demonstrated the following degrees of mitral regurgitation: none/trivial, 192 (68.8\%); mild, 66 (23.6\%); moderate, 15 (5.4\%); and severe, 6 (2.2\%). Five-year Kaplan-Meier survival was $96.6 \% \pm 1.5 \%$, with $93.8 \% \pm 1.6 \%$ freedom from reoperation.

Conclusions: Robotic mitral valve repair is safe and is associated with good midterm durability. Further long-term follow-up is necessary.

$\mathrm{M}$ itral valve repair (MVP) surgery has advanced markedly over the past 25 years. ${ }^{1-4}$ Excellent long-term MVP outcomes, compared with prosthetic replacements, have shifted the focus of patients, cardiologists, and surgeons toward improving repair techniques, including less-invasive access. In the last 10 years, minimally invasive MVPs for patients with degenerative (myxomatous) disease have been similar to or better than those yielded by traditional sternotomy operations. ${ }^{5-11}$ Minimally invasive repairs with nonrobotic endoscopic approaches have been described. ${ }^{5,8,9}$ Few surgeons have demonstrated success in complex combined leaflet, annular, and chordal repairs by using these techniques due, in part, to the ergonomic difficulties associated with long manual instruments and limited operative precision in space-limited cardiac chambers. This report describes the clinical outcomes in 300 patients who underwent MVP with advanced robotic technology. In this setting articulated instrumentation enables robotic tissue telemanipulation coupled with high-definition, 3-dimensional secondary vision. 


\author{
Abbreviations and Acronyms \\ FDA $=$ US Food and Drug Administration \\ $\mathrm{MR}=$ mitral regurgitation \\ $\mathrm{MV}=$ mitral valve \\ MVP $=$ mitral valve repair \\ TEE $=$ transesophageal echocardiography \\ TTE $=$ transthoracic echocardiography
}

\section{Materials and Methods Study Population}

Between May 2000 and November 2006, 300 patients underwent MVP at the University Health System of Eastern Carolina and East Carolina University with the da Vinci robotic surgical system (Intuitive Surgical, Inc, Sunnyvale, Calif). During the same time period, an additional 646 mitral valve (MV) operations were performed at our center either through a sternotomy or right minithoracotomy with videoscopic assistance. Study protocols were approved by the University Health System of Eastern Carolina Institutional Review Board, and informed consent was obtained from each patient. All patients with degenerative MV disease were considered to be candidates for a robotic repair. Exclusion criteria included an extensively calcified MV annulus, preoperative planning for an MV replacement, severe pulmonary hypertension (pulmonary artery systolic pressure $>70 \mathrm{~mm} \mathrm{Hg}$ ), poor left ventricular function (ejection fraction $<20 \%$ ), and significant coronary artery disease necessitating multivessel bypass grafting.

Routine preoperative evaluations included a history and physical examination, chest radiography, and 12-lead electrocardiography. In patients older than 40 years, either angiography or computed tomography was used to rule out significant coronary disease. Every patient underwent either preoperative transthoracic echocardiography (TTE) or transesophageal echocardiography (TEE).

\section{Operative Technique}

Two-dimensional TEE with a color flow Doppler study was performed in the operating room to confirm the plan for each mitral reconstruction. Acquired images included 4-chamber views, as well as short- and long-axis 2-chamber views, at both the midesophageal and deep transgastric levels. Preoperative and postoperative right and left ventricular function were assessed at midchamber in the short-axis dimension. Operations were conducted through a 3- to 4-cm right inframammary incision through the fourth or fifth intercostal space, as well as three $1-\mathrm{cm}$ robotic arm ports placed radially around the incision. After the instrument arms were inserted, standard repair techniques were used for leaflet resections and reconstructions, chordal procedures (including chordal transfers), and polytetrafluorethylene neochordal construction*, and all-suture knot tying was done intracorporeally with the robotic arms. In every case an annuloplasty was performed with a Cosgrove-Edwards band (Edwards Lifesciences, Irvine, Calif) secured either with 2-0 Cardioflon sutures (Peters, Inc, Paris, France) or nitinol U-clips (Medtronic, Inc, Minneapolis, Minn).

\footnotetext{
*Gore-Tex neochord, W. L. Gore \% Associates, Inc, Newark, Del.
}

Cardiopulmonary bypass was established through femoral vessel cannulation. Cold $\left(4^{\circ} \mathrm{C}\right)$ antegrade crystalloid cardioplegia and a transthoracic aortic crossclamp (Scanlan International, Minneapolis, Minn) provided myocardial protection during the arrest period. All mitral repairs were performed by a single operative console surgeon; however, multiple patient-side surgeons participated. More details of our robotic operative approach and repair techniques have been published previously. ${ }^{11-13}$

\section{Follow-up Evaluation}

All surviving patients were examined and evaluated 6 weeks postoperatively. Our recommended echocardiographic follow-up includes TTE done between 3 and 6 months after surgical intervention and annually thereafter. Interval clinical follow-up was done through direct contact with patients, their referring physicians, or both or through queries of social security number and national death registries.

\section{Data Collection and Statistical Methods}

All perioperative and outcomes data were collected contemporaneously into a proprietary clinical cardiovascular information system. Data are expressed as means $\pm \mathrm{SD}$. The Kaplan-Meier curves were calculated by using R version 2.41 (http://www.r-project.org).

\section{Results}

\section{Patient Characteristics}

Table 1 lists preoperative demographic information for all patients. Participants were enrolled consecutively, and the first 20 patients constituted a phase I US Food and Drug Administration (FDA) safety and efficacy trial (G000023). ${ }^{11}$ The next 22 patients were included in a phase II FDA multicenter trial (G000295). ${ }^{12}$ The remaining patients had repairs done after FDA approval of the da Vinci surgical system for use in intracardiac surgery.

\section{Operative Data}

During this time period, 309 patients underwent an intent-totreat robotic MVP. There were no intraoperative conversions to a sternotomy. A total of 9 cases were converted to a minimally invasive approach by using the same incision and videoscopic assistance. The reasons for these conversions included early da Vinci system malfunction $(n=3)$, poor surgical exposure $(n=4)$, external instrument conflicts $(n=1)$, and need for MV replacement $(n=1)$.

Table 2 shows the variety of repair techniques used in this series, ranging from simple annuloplasty bands with or without a leaflet resection to more complex repairs involving chordal transfers $(n=81)$, polytetrafluoroethylene neochordal implantations $(n=48)$, and a combination of chordal procedures $(n=23)$ for the management of Barlows disease and anterior leaflet prolapse pathologies. Also shown are concomitant procedures and cardiopulmonary bypass times.

\section{Mortality and Morbidity}

In this series of 300 robot-assisted cases, there were no intraoperative device- or perfusion-related patient complications. 
TABLE 1. Preoperative demographics

\begin{tabular}{lc}
\hline \multicolumn{1}{c}{ Characteristics } & \\
\hline Age (y), mean \pm SD & $56.5 \pm 12.8$ \\
Age (y), range & $19-80$ \\
Female sex & $107(35.7)$ \\
Body mass index, mean \pm SD & $25.7 \pm 4.1$ \\
New York Heart Association & \\
Class I & $55(18.3)$ \\
Class II & $167(55.7)$ \\
Class III & $74(24.7)$ \\
Class IV & $4(1.3)$ \\
Comorbidities & \\
Congestive heart failure & $242(80.7)$ \\
Hypertension & $120(40.0)$ \\
Smoking history & $102(34.0)$ \\
Diabetes & $19(6.3)$ \\
Renal insufficiency & $1(0.3)$ \\
Pulmonary hypertension & $49(16.3)$ \\
Atrial fibrillation/atrial flutter & $54(18.0)$ \\
Coronary artery disease & $26(8.7)$ \\
Peripheral vascular disease & $3(1.0)$ \\
Stroke & $8(2.7)$ \\
Previous cardiac surgery & $2(0.7)$ \\
Echocardiographic details & \\
LVEF, mean \pm SD & $57.8 \pm 8.5$ \\
$>45 \%$ & $269(89.7)$ \\
$35 \%-45 \%$ & $25(8.3)$ \\
$25 \%-35 \%$ & $5(1.7)$ \\
Se\%-25\% & $1(0.3)$ \\
Severe mitral insufficiency & $272(90.7)$ \\
\hline & $1(0.3)$ \\
\hline
\end{tabular}

Values are presented as number (percentage), where shown. SD, Standard deviation; $L V E F$, left ventricular ejection fraction.

Postoperative complications are shown in Table 3. There were $2(0.7 \%)$ deaths within 30 days, one related to a protamine reaction and the other to right ventricular failure. In addition, there were $6(2.0 \%)$ late mortalities. Four of these patients died from noncardiac causes. Two patients died after MV reoperations: one died from a stroke and multiorgan failure, and the other died from ventricular failure.

The mean intensive care unit length of stay was $32.4 \pm$ 67.3 hours, with $286(95.3 \%)$ patients extubated within 24 hours. The mean hospital stay was $5.2 \pm 4.2$ days, with $58.3 \%$ of patients discharged by postoperative day 4 . Thirty-five (11.7\%) patients were readmitted within 30 days of the operation for respiratory problems $(n=13)$, atrial arrhythmias $(n=6)$, pericarditis $(n=2)$, syncope $(n=2)$, valve dysfunction $(n=4)$, or other causes $(n=8)$.

Reoperation was required in $16(5.3 \%)$ patients at a mean of $319 \pm 327$ days (range, 15-946 days) from the original operation. Eight reoperations occurred within 71 days (mean, $42 \pm 24$ days) of the original operation, and the remaining 8 occurred after 305 days (mean $596 \pm 230$ days). Seven

\section{TABLE 2. Operative details}

\begin{tabular}{|c|c|}
\hline \multicolumn{2}{|l|}{ Mitral valve repair type } \\
\hline Annuloplasty band & $300(100)$ \\
\hline Median size (range, 26-40 mm) & $32 \mathrm{~mm}$ \\
\hline Annuloplasty alone & $40(13.3)$ \\
\hline Edge-to-edge + annuloplasty & $6(2.0)$ \\
\hline Leaflet resection + annuloplasty & $72(24.0)$ \\
\hline $\begin{array}{l}\text { Leaflet resection }+ \text { sliding plasty with } \\
\text { or without chordal procedure }+ \text { annuloplasty }\end{array}$ & $75(25.0)$ \\
\hline $\begin{array}{l}\text { Chordal procedure (no leaflet resection) } \\
\quad+\text { annuloplasty }\end{array}$ & $40(13.3)$ \\
\hline $\begin{array}{l}\text { Leaflet resection }+ \text { chordal procedure } \\
\quad+\text { annuloplasty }\end{array}$ & $60(20.0)$ \\
\hline Leaflet repair + annuloplasty & $7(2.3)$ \\
\hline \multicolumn{2}{|l|}{ Concomitant procedures } \\
\hline CryoMaze atrial fibrillation ablation & $31(10.3)$ \\
\hline $\begin{array}{l}\text { Radiofrequency or microwave atrial } \\
\text { fibrillation ablation }\end{array}$ & $22(7.3)$ \\
\hline Patent foramen ovale closure & $33(11)$ \\
\hline Atrial septal defect closure & $1(0.3)$ \\
\hline Minimally invasive coronary artery bypass & $2(0.7)$ \\
\hline \multicolumn{2}{|l|}{ Perfusion details } \\
\hline Cardiopulmonary bypass time (min), mean \pm SD & $158.7 \pm 41.8$ \\
\hline Crossclamp time (min), mean $\pm S D$ & $122.1 \pm 33.3$ \\
\hline
\end{tabular}

failures were within the first 100 operations, and 9 occurred among the last 200 operations.

Reasons for reoperation included progression of native disease $(n=3)$, valve endocarditis $(n=1)$, or technical failures $(n=10)$; these included anterior leaflet systolic anterior motion $(n=2)$. Technical failures included 7 patients having a band dehiscence, with 4 (or 4\%) among the first 100 cases but only 3 (or $1.5 \%$ ) among the last 200 cases. In the groups undergoing reoperations, a prosthetic valve replacement was performed in 13 patients, and rerepair was possible in 3 individuals. The extent of immediate postoperative mitral regurgitation (MR) for the 16 patients undergoing reoperations ranged from none $(\mathrm{n}=10)$ to trace $(\mathrm{n}=5)$ to mild to moderate $(\mathrm{n}=1)$.

\section{Echocardiographic Studies and Patient Follow-up}

As demonstrated in Table 4, all 300 patients underwent intraoperative postrepair TEE, with 280 (93.3\%) patients having no MR. Follow-up TTE studies were obtained in 279 (93\%) patients, with a mean follow-up of $815 \pm 459$ days. Reasons for failure to obtain follow-up TTE studies included patient refusal to participate in the study $(\mathrm{n}=8)$, early death $(\mathrm{n}=2)$, or loss of direct patient contact $(\mathrm{n}=11)$. Follow-up TTE revealed the following degrees of MR: none to trace $(\mathrm{n}=192$, $68.8 \%)$, mild $(\mathrm{n}=66,23.6 \%)$, moderate $(\mathrm{n}=15,5.3 \%)$, and severe $(n=6,2.2 \%)$. Every one of the patients with severe MR during follow-up has undergone a reoperation. 
TABLE 3. Postoperative outcomes and complications

\begin{tabular}{lc}
\hline 30-d Mortality & $2(0.7)$ \\
Late mortality & $6(2.0)$ \\
Myocardial infarction & $3(1.0)$ \\
Stroke (minor) & $2(0.7)$ \\
Reversible neurologic injury & $2(0.7)$ \\
Prolonged mechanical ventilation (>48 h) & $7(2.3)$ \\
Bleeding requiring reoperation & $7(2.3)$ \\
Any blood product transfusion & $87(29.0)$ \\
pRBC & $46(15.3)$ \\
FFP & $20(6.7)$ \\
Platelets & $23(7.7)$ \\
Infection & $1(0.3)$ \\
Renal insufficiency & $6(2.0)$ \\
Atrial fibrillation/atrial flutter & $83(27.7)$ \\
Pleural effusion & $28(9.3)$ \\
Aortic dissection & $0(0)$ \\
Femoral arterial or vein complication & $0(0)$ \\
Hospital length of stay (d), mean \pm SD & $5.2 \pm 4.2$ \\
Readmission within $30 \mathrm{~d}$ & $35(11.7)$ \\
Long-term repair failures and second operation & \\
Mitral valve replacement & $13(4.3)$ \\
Mitral valve rerepair & $3(1.0)$ \\
\hline
\end{tabular}

Values are presented as number (percentage), where shown. $p R B C$, Packed red blood cells; FFP, fresh frozen plasma; $S D$, standard deviation.

Of the 298 early survivors, follow-up was $100 \%$ at 1179 \pm 623 days. Five-year Kaplan-Meier survival and freedom from reoperation rates were $96.6 \% \pm 1.5 \%$ and $93.8 \% \pm$ $1.6 \%$, respectively (Figure 1 ).

\section{Discussion}

We report the largest single-center series to date of robotic MVP. In this study we demonstrate that these procedures can be performed safely and with excellent results.

Since Carpentier's 1983 "French correction" article ${ }^{14}$ demonstrating the benefits of performing a functional mitral repair rather than a valve replacement, there has been a steadily increasing interest in mitral reconstruction in North America. Compared with prosthetic replacements, repairs increased survival and minimized thromboembolism, endo-

TABLE 4. Echocardiographic data

\begin{tabular}{lccc}
\hline & $\begin{array}{c}\text { Preoperative, } \\
\mathbf{n}=\mathbf{3 0 0}(\%)\end{array}$ & $\begin{array}{c}\text { After repair, } \\
\mathbf{n}=\mathbf{3 0 0}(\%)\end{array}$ & $\begin{array}{c}\text { Follow-up, } \\
\mathbf{n}=\mathbf{2 7 9}(\%)\end{array}$ \\
\hline $\begin{array}{l}\text { MR severity } \\
\text { None }\end{array}$ & $0(0)$ & $280(93)$ & $125(44.8)$ \\
Trace & $0(0)$ & $12(4)$ & $67(24)$ \\
Mild & $0(0)$ & $5(1.6)$ & $66(23.6)$ \\
Moderate & $28(9.3)$ & $3(1)$ & $15(5.3)$ \\
Severe & $272(90.7)$ & $0(0)$ & $6(2.2)$ \\
\hline
\end{tabular}

$M R$, Mitral regurgitation.
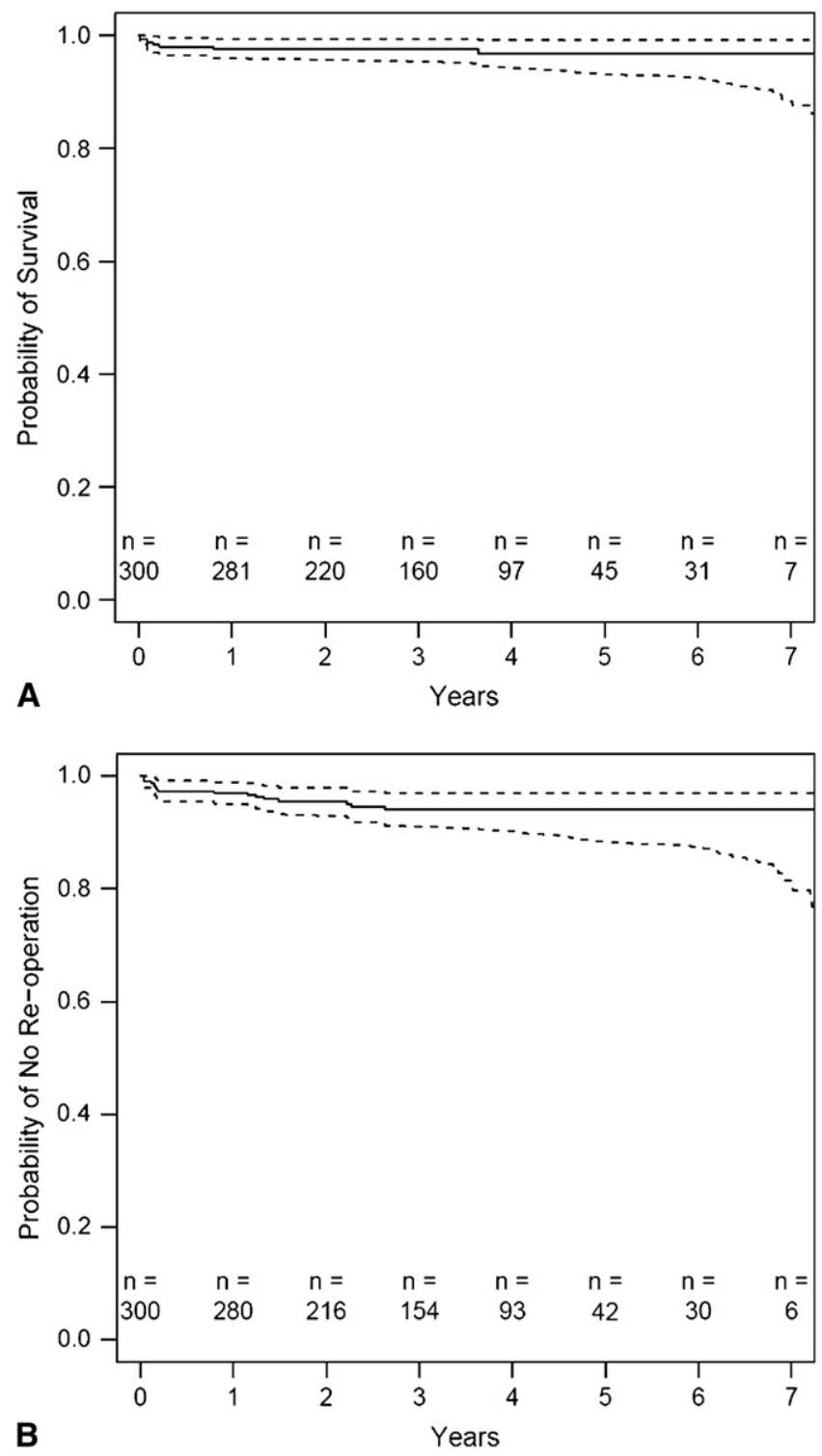

Figure 1. A, Kaplan-Meier survival curve. Dotted lines, Confidence interval. Patients at risk at each year are also shown. B, Kaplan-Meier freedom from reoperation. Dotted lines, Confidence interval. Patients at risk at each year are also shown.

carditis, and anticoagulation-related complications. Carpentier, Cosgrove, and David each showed a $92 \%$ to $95 \%$ reoperative freedom with repairs when performed through a traditional sternotomy. ${ }^{1,15-18}$ These benefits convinced cardiologists and surgeons alike to recommend mitral repair for symptomatic patients with significant MR from degenerative (myxomatous) disease.

A variety of minimal-access approaches have been developed to perform MVPs, including limited sternotomies and videoscopic minithoracotomies $(3-4 \mathrm{~cm})$ using 2-dimensional 
video assistance. Casselman and colleagues ${ }^{19}$ have recently reported a large series of videoscopic MVPs and MV replacements with lower $3.6 \%$ reoperative rates. At our institution, ${ }^{20}$ since 1996, 514 mitral repairs or replacements have been done by using this method, with results similar to those of Vanermen and colleagues. These patients either preceded our adoption of robotic techniques or met our exclusion criteria for using the da Vinci system. With this video-assisted approach, however, significant ergonomic and visual limitations persist, in particular related to complex mitral repairs involving chordal transfer, sliding valvuloplasty, and partial leaflet transposition. Performance of a truly endoscopic mitral repair through thoracic ports requires 3-dimensional visualization and articulated instrumentation for these complex cases.

The da Vinci robotic surgical system enables surgeons to perform complex mitral repairs through port incisions using optimized, high-definition visualization and fine dexterity. ${ }^{21}$ Through magnified telepresence, the operator becomes ensconced in the anatomic landscape without distraction while instrument tips are telemanipulated through 7 degrees of ergonomic freedom. Ambidextrous access to the entire subvalvular chordal apparatus and papillary muscles, as well as all leaflet topography, becomes possible without instrument-tip tremor. Both digital and analog camera zooming make visualization interactive, and dynamic foot-clutch instrument realignment further enables optimal hand position for maximal ergonomic access to the operative zone.

Carpentier and associates ${ }^{22}$ and Autschbach and colleagues $^{23}$ first used prototypes of this robotic device in 1998 to perform mitral repairs. Beginning in 2000, 2 FDA investigational device trials provided the pathway for 2002 approval for intracardiac use in the United States. This report details midterm clinical results from 300 consecutive daVinci Surgical System MVPs, including patients from the inaugural FDA studies. ${ }^{11,12}$ In this single-center experience 245 repairs involved more than a simple annuloplasty ring, edge-to-edge repair, or both, and $52(17.3 \%)$ were for bileaflet prolapse. With this approach, the transfusion requirements and lengths of stay in the hospital are similar to those of other robotic repair series; Woo and Nacke ${ }^{24}$ reported blood product transfusion rates, with $15.3 \%$ requiring packed red blood cell transfusions. In addition, rates of re-exploration for bleeding compare favorably with those for minithoracotomy and hemisternotomy mitral repair series. ${ }^{19,25}$ Furthermore, 58\% and $75 \%$ of patients in the present series were discharged by postoperative days 4 and 5, respectively, with a readmission rate of only $11 \%$. In contrast, Tatooles and associates ${ }^{26}$ reported a mean hospitalization of only 2.7 days; however, patients in their study experienced a $28 \%$ readmission rate.

In the current series $5.3 \%$ of patients required a reoperation within 2 years (mean, $319 \pm 353$ days). These results are similar to those of the FDA multicenter trial ${ }^{11,12}$ and compare favorably with results of several sternotomy-based series, which reported $5 \%$ to $6 \%$ early repair failures. ${ }^{1-3,16}$ Video review of the primary operation was done for all failed repairs. Reoperations were found to result from either technical causes or disease progression. Seven patients had an annuloplasty ring dehiscence, which occurred primarily at the right fibrous trigone and posterior commissure. Early in the series, a rigid transthoracic retractor was used for exposure, which prevented optimal access to this area. It is likely that instrument retraction and multiple annular suture passes weakened the tissue matrix, thus resulting in dehiscence. Annuloplasty band failures were balanced between clip and suture fixation. Two patients had incomplete reduction of the posterior leaflet, eventuating in refractory anterior leaflet septal motion. In patients with disease progression undergoing reoperation, 2 reoperations failed because of recurrent annular dilatation with return of central regurgitation, and 1 patient had progressive bileaflet prolapse. A detailed reviewed of the nature of these reoperations will be discussed in a separate publication ${ }^{27}$.

Temporally, 7 failures occurred among the first 100 cases (7\% failure rate); early on, the lack of tactile feedback could have initially limited the ability to assess suture depth and tension, resulting in repair failure. Developments in robotic technology, such as an articulated robotic atrial retractor, which provides ideal anatomic exposure to all mitral regions, and imaging improvements that permit magnified and 3-dimensional vision and surrogate feedback that projects "visual tactility," now enable surgeons to understand tissue deformational characteristics and suture remodeling with tightening. This might have contributed to the improved $4.5 \%(\mathrm{n}=9)$ failure rate that was observed among the next 200 cases. Clearly, experience gained over the 6-year study duration resulted in the performance of more complex repairs done with greater facility and fewer failures. ${ }^{13} \mathrm{We}$ anticipate that use of 3-dimensional TEE for intraoperative planning and analysis will contribute to further improvements in these results.

There are several important limitations to this study. First, this is a single-center observational analysis without an adequate comparison sternotomy experience other than historical data. Although patients had the option of having a traditional sternotomy-based operation, most were referred specifically for a minimally invasive operation, which precluded the option of randomization.

Second, follow-up echocardiograms were not interpreted by a single echocardiographer. Because approximately $40 \%$ of our patients are from out of the state of North Carolina, we had to rely on the patient's local cardiologist for echocardiographic follow-up.

Finally, longer-term follow-up is necessary to fully assess whether robotic MVP is equivalent to or better than the traditional sternotomy-based MVP approach. As a continuous observational series, however, inclusion of FDA trial data (first cases done in the United States), continuation as a consecutive series, prospective protocol planning, contemporaneous data collection, and 93\% echocardiographic follow-up add strength to this prospective study. 
The introduction of this robotic technology into cardiac surgery has followed the typical technology adoption sequence, with early enthusiasm, early failures, and then more experience leading to improved performance by some surgeons. Controlled application by experienced surgeons remains the ideal way to initiate new technology in a safe and efficacious manner. We have demonstrated that complex repairs of the MV can be done endoscopically through robotic surgical telemanipulation, with excellent results. These repairs are durable out to an intermediate term; continued follow-up will be important for establishing the long-term efficacy of robotic MV operations. Until then, we anticipate that this study will serve as a springboard for further development and application of robotic cardiac surgery.

We thank the clinical research nurses and assistants (Malissa J. Harris, RN, BSN; Nancy C. Blake, RN, BSN; and Stephanie Russell) and the clinical instructors (Jason Felger, MD; Gil Bolotin, MD; Victor Chu, MD; Saqib Masroor, MD; Richard Cook, MD; Simon C. Moten, MD; and Karen Gersch, MD).

\section{References}

1. Braunberger E, Deloche A, Berrebi A, Abdallah F, Celestin JA, Meimoun P, et al. Very long-term results (more than 20 years) of valve repair with Carpentier's techniques in nonrheumatic mitral valve insufficiency. Circulation. 2001;104(suppl 1):I8-11.

2. Mohty D, Orszulak TA, Schaff HV, Avierinos JF, Tajik JA, EnriquezSarano M. Very long-term survival and durability of mitral valve repair for mitral valve prolapse. Circulation. 2001;104(suppl 1):I1-7.

3. Mohty D, Enriquez-Sarano M. The long-term outcome of mitral valve repair for mitral valve prolapse. Curr Cardiol Rep. 2002;4:104-10.

4. Gillinov AM, Cosgrove DM, Blackstone EH, Diaz R, Arnold JH, Lytle BW, et al. Durability of mitral valve repair for degenerative disease. J Thorac Cardiovasc Surg. 1998;116:734-43.

5. Casselman FP, Van Slycke S, Dom H, Lambrechts DL, Vermeulen Y, Vanermen H. Endoscopic mitral valve repair: feasible, reproducible, and durable. J Thorac Cardiovasc Surg. 2003;125:273-82.

6. Cohn LH, Adams DH, Couper GS, Bichell DP, Rosborough DM, Sears SP, et al. Minimally invasive cardiac valve surgery improves patient satisfaction while reducing costs of cardiac valve replacement and repair. Ann Surg. 1997;226:421-8.

7. Cosgrove DM 3rd, Sabik JF, Navia JL. Minimally invasive valve operations. Ann Thorac Surg. 1998;65:1535-9.

8. Felger JE, Chitwood WR Jr, Nifong LW, Holbert D. Evolution of mitral valve surgery: toward a totally endoscopic approach. Ann Thorac Surg. 2001;72:1203-9.

9. Mohr FW, Falk V, Diegeler A, Walther T, Gummert JF, Bucerius J, et al. Computer-enhanced "robotic" cardiac surgery: experience in 148 patients. J Thorac Cardiovasc Surg. 2001;121:842-53.
10. Navia JL, Cosgrove DM 3rd. Minimally invasive mitral valve operations. Ann Thorac Surg. 1996;62:1542-4.

11. Nifong LW, Chu VF, Bailey BM, Maziarz DM, Sorrell VL, Holbert D, et al. Robotic mitral valve repair: experience with the da Vinci system. Ann Thorac Surg. 2003;75:438-43.

12. Nifong LW, Chitwood WR, Pappas PS, Smith CR, Argenziano M, Starnes VA, et al. Robotic mitral valve surgery: a United States multicenter trial. J Thorac Cardiovasc Surg. 2005;129:1395-404.

13. Rodriguez E, Kypson AP, Moten SC, Nifong LW, Chitwood WR Jr. Robotic mitral surgery at East Carolina University: a 6 year experience. Int J Med Robot. 2006;2:211-5.

14. Carpentier A. Cardiac valve surgery-the "French correction." J Thorac Cardiovasc Surg. 1983;86:323-37.

15. Cerfolio RJ, Orzulak TA, Pluth JR, Harmsen WS, Schaff HV. Reoperation after valve repair for mitral regurgitation: early and intermediate results. J Thorac Cardiovasc Surg. 1996;111:1177-84.

16. David TE, Ivanov J, Armstrong S, Christie D, Rakowski H. A comparison of outcomes of mitral valve repair for degenerative disease with posterior, anterior, and bileaflet prolapse. J Thorac Cardiovasc Surg. 2005; $130: 1242-9$

17. David TE, Ivanov J, Armstrong S, Rakowski H. Late outcomes of mitral valve repair for floppy valves: implications for asymptomatic patients. J Thorac Cardiovasc Surg. 2003;125:1143-52.

18. David TE, Omran A, Armstrong S, Sun Z, Ivanov J. Long-term results of mitral valve repair for myxomatous disease with and without chordal replacement with expanded polytetrafluoroethylene sutures. J Thorac Cardiovasc Surg. 1998;115:1279-86.

19. Casselman FP, Van Slycke S, Wellens F, De Geest R, Degrieck I, Van Praet $\mathrm{F}$, et al. Mitral valve surgery can now routinely be performed endoscopically. Circulation. 2003;108(suppl 1):II48-54.

20. Chitwood WR Jr. Current status of endoscopic and robotic mitral valve surgery. Ann Thorac Surg. 2005;79(suppl):S2248-53.

21. Murphy DA, Miller JS, Langford DA. Endoscopic robotic mitral valve surgery. J Thorac Cardiovasc Surg. 2007;133:1119-20.

22. Carpentier A, Loulmet D, Aupecle B, Kieffer JP, Tournay D, Guibourt P, et al. [Computer assisted open heart surgery. First case operated on with success]. Comptes rendus de l'Academie des sciences. 1998;321:437-42.

23. Autschbach R, Onnasch JF, Falk V, Walther T, Kruger M, Schilling LO, et al. The Leipzig experience with robotic valve surgery. J Card Surg. 2000; $15: 82-7$.

24. Woo YJ, Nacke EA. Robotic minimally invasive mitral valve reconstruction yields less blood product transfusion and shorter length of stay. Surgery. 2006;140:263-7.

25. Mihaljevic T, Cohn LH, Unic D, Aranki SF, Couper GS, Byrne JG. One thousand minimally invasive valve operations: early and late results. Ann Surg. 2004;240:529-34.

26. Tatooles AJ, Pappas PS, Gordon PJ, Slaughter MS. Minimally invasive mitral valve repair using the da Vinci robotic system. Ann Thorac Surg. 2004;77:1978-84.

27. Rodriguez E, Narron J, Chu MW, Gersch K, Nifong LW, Chitwood WR Jr. "Robotic Mitral Valve Repairs Requiring Reoperations" Innovations Technology \& Techniques in Cardiothoracic and Vascular Surgery, 3(1):12-15, January 2008. 